\title{
The Influence of Low Temperature on the Corrosion of EH40 Steel in a NaCl Solution
}

\author{
Yuanyuan Shen ${ }^{1}$, Yaohua Dong ${ }^{2,1, *}$, Hengding Li $^{1}$, Xueting Chang ${ }^{1}$, Dongsheng Wang ${ }^{1}$, \\ Qinghong $\mathrm{Li}^{1}$ and Yansheng Yin ${ }^{1}$ \\ ${ }^{1}$ College of Ocean Science and Engineering, Shanghai Maritime University, Shanghai 201306, China; \\ ${ }^{2}$ School of Mechanical Engineering, Shanghai Jiaotong University, Shanghai 200240, China \\ *E-mail: yhdong@ shmtu.edu.cn
}

doi: $10.20964 / 2018.07 .55$

Received: 3 April 2018 / Accepted: 4 May 2018 / Published: 5 June 2018

The high strength ocean engineering structural steel EH40 exhibited great potential for the building of polar expedition ships due to high performance strength, relevant low-temperature impact toughness, prominent ship plate steel extensions, and outstanding weldability. The corrosion behavior of modified EH40 steel in low-temperature $\left(0^{\circ} \mathrm{C}\right) 3.5 \mathrm{Wt} \% \mathrm{NaCl}$ solution over a 56-day period was investigated using mass loss techniques, surface characterization, component analysis, and electrochemical measurements. The results showed that the corrosion rate of EH40 steel in low-temperature artificial seawater was relatively high compared to artificial seawater at room-temperature after 14 days of immersion. Notably, in the low-temperature $\mathrm{NaCl}$ solution, the scale deposits consisted mainly of $\mathrm{Fe}\left(\mathrm{Cl}_{\mathrm{x}} \mathrm{O}_{\mathrm{y}}\right)$ under which, corrosion pits were initiated. Moreover, uneven corrosion products formed on the steel surface and the size of the pit gradually increased with immersion time. In contrast, for the room temperature $\mathrm{NaCl}$ solution, a compact and thick corrosion product film covered the steel surfaces, protecting the steel from further corrosion and a characteristic uniform corrosion was present in the steel.

Keywords: EH40 steel; extreme cold environment; pitting corrosion; microstructure; EIS

\section{$\underline{\text { FULL TEXT }}$}

(C) 2018 The Authors. Published by ESG (www.electrochemsci.org). This article is an open access article distributed under the terms and conditions of the Creative Commons Attribution license (http://creativecommons.org/licenses/by/4.0/). 